\title{
A toolbox for glider data processing and management
}

\author{
C. Troupin ${ }^{\mathrm{a}}$, J.P. Beltran ${ }^{\mathrm{a}}$, E. Heslop ${ }^{\mathrm{a}}$, M. Torner ${ }^{\mathrm{a}}$, B. Garau ${ }^{\mathrm{b}}$, J. Allen $^{\mathrm{a}}$, \\ S. Ruiz ${ }^{\mathrm{c}}$, J. Tintoréa,c \\ ${ }^{a}$ Balearic Islands Coastal Ocean Observing and Forecasting System (SOCIB), Parc Bit, \\ Naorte, Bloc A 2nd floor, 3rd door, Palma de Mallorca, SPAIN \\ ${ }^{b}$ Centre for Maritime Research and Experimentation, La Spezia, Italy \\ ${ }^{c}$ Mediterranean Institute for Advanced Studies (IMEDEA), C/ Miquel Marqus, 21 - 07190 \\ Esporles - Illes Balears, SPAIN
}

\begin{abstract}
We present a complete set of freely available MATLAB/Octave scripts called the SOCIB Glider Toolbox (https://github.com/socib/glider_toolbox). This new toolbox automates glider data processing functions, including thermal lag correction, quality control and graphical outputs. While the scientific value of the glider platform has been proven, the experience for the glider data user is far from perfect or routine. Over the last 10 years, ocean gliders have evolved such that they are now considered a core component of multi-platform observing systems and multi-disciplinary process studies ; we now have a generic processing system that appropriately complements glider capability.

In an ideal world, a simple connection to a glider would provide oceanographic data ready for scientific application in an intuitive, familiar format; the reality has been somewhat different. Up till now users have faced several timeconsuming tasks that prevent them from directly and efficiently extracting new oceanographic knowledge from the acquired data. The SOCIB glider toolbox covers all stages of the data management process, including: metadata aggregation, raw data download, data processing, data correction and the automatic generation of data products and figures. It is designed to be operated either in real-time or in delayed mode, and to process data from two of the most widely
\end{abstract}

\footnotetext{
${ }^{*}$ Corresponding author

Email address: ctroupin@socib.es (C. Troupin)
} 
used and commercially exploited glider platforms, Slocum gliders and SeaGliders. The SOCIB glider toolbox is ready to accelerate glider data integration and promote oceanographic discovery.

Keywords: Gliders, Autonomous underwater vehicles, Observing systems, Processing toolbox, Glider data, Thermal Lag

\section{Introduction}

In recent years, gliders have emerged as an essential tool for oceanographic monitoring, thanks to their capacity to operate autonomously in all weather conditions, for missions up to several months, and with higher sampling resolution than generally obtained with research vessels. Glider vehicles are able to autonomously dive to typically up to $1000 \mathrm{~m}$ water depth and return to the surface navigating along a pre-determined sampling path, balancing buoyancy against lift for forward motion. Thanks to these characteristics, gliders have progressively become an integral component of the observational platforms available to ocean science, providing critical information for climate change research, improving forecasts through data assimilation (Shulman et al., 2009; Dobricic et al., 2010; Gangopadhyay et al., 2013), and now also providing in-situ data from the hurricane pathway to improve the prediction (Baltes et al., 2014). In the future glider missions could automatically adjust missions to reach locations that would optimally sample oceanic fields (Álvarez \& Mourre, 2012; Mourre \& Álvarez, 2012) leading to, for example, improved model forecasts. Gliders are also used in multi-platform studies, where their measurements are combined with those of other instruments, such as satellite altimeter (Bouffard et al., 2010, 2012; Ruiz et al., 2009) or high-frequency radar (Troupin et al., 2015) to improve the description of mesoscale features.

Notwithstanding these many advantages, autonomous platforms such as gliders, have not yet reached the same level of maturity as more traditional oceanographic monitoring platforms (where the "plug-in/plug-out" availability of data has become the norm) with well established data download, preprocessing, pro- 
cessing and quality control procedures. This implies that a newcomer to glider data analysis is exposed to a number of issues and time-consuming tasks that are not common when processing data from more traditional platforms. Gliders from different manufacturers generate data files with different formats, and software covering the whole data processing chain is not provided with these platforms. Generally, the data collected during a glider deployment are provided as a collection of files in binary and/or text format, separated either on a navigational segment basis (Teledyne Webb Research, 2014) or on an individual dive basis (Seaglider ${ }^{\mathrm{TM}}$, http://www.km.kongsberg.com), and although the conversion from binary to text files can be performed using manufacturer programs, this can be the limit of manufacturer supplied processing software. Consequently, there has not been a homogeneous and consistent method of preprocessing and processing the large quantities of raw glider data: output from the different manufacturer platforms, the different sensors and stored in either the navigation or science computer.

In the frame of European initiatives, efforts have been made towards a general improvement of the data processing step, namely through the work of EGO (Everyone's Gliding Observatories, www.ego-network.org), GROOM (Gliders for Research, Ocean Observation and Management, www.groom-fp7.eu) and JERICO (Towards a Joint European Research Infrastructure network for Coastal Observatories, www.jerico-fp7.eu). The main outcomes have been an enhanced collaboration between the various glider operators across Europe through sharing of knowledge and best practice, as well as some code for data processing (https://forge.ifremer.fr/svn/oo-ego-gliders/trunk, requiring a $\log$ in account). However there is still work pending to bring glider data to the usability level of more traditional platforms. One of these tasks is to create a user-friendly pre-processing and processing chain, which is covered in this article. Another is to establish international best practice for glider data quality control and delayed mode or post-mission calibration, an issue that is largely covered here in addressing the thermal lag correction in salinity, but which is also part of on-going work in the glider community, across the different 
variables and sensors available.

The Balearic Islands Coastal Observing and Forecasting System (SOCIB, Tintoré et al., 2013), with an active glider fleet in the Balearic region, has developed a glider toolbox specifically to tackle the aforementioned issues. This toolbox is based on the previous code developed at IMEDEA and SOCIB by B Garau. SOCIB has acquired an extensive experience in glider technology, both with Slocum and Seaglider platforms. Since 2005 over 55 deployments have been performed, totalling over 900 days and 10,000 nautical miles at sea, and collecting more than 26,000 water column profiles. The development of a glider data processing toolbox therefore evolved naturally from the need to operate and manage these data streams in real-time and delayed mode (Cusí et al., 2013), and to address issues such as thermal-lag (Garau et al., 2011), which can affect glider salinity data. With the increasing number of glider users worldwide, a toolbox designed to deal with the specific issues of the glider platform is a timely development.

There have been earlier toolboxes, for instance the Glider Data Conversion (Maher, 2014) or the Slocum Power Tool (Kerfoot, 2014). However, the advantage of the SOCIB toolbox is its support for the rapid processing and consistent organization of data from both Seaglider ${ }^{\mathrm{TM}}$ and Slocum data types, leading to a well-defined archive of deployments and unified datasets in a self-documented portable format (Network Common Data Form, NetCDF, Rew \& Davis, 1990), with user selected processing levels for each deployment. The toolbox is modular and scalable, and incorporates a suite of useful utilities that can be adopted as stand-alone pieces of code.

In this paper we describe the main functionalities of the SOCIB Glider Toolbox and provide initial guidelines for potential new users, ranging from scientists interested in process studies to data centres requiring data management for glider fleets. Outputs and figures obtained with data from a SOCIB mission (CANALES-Oct-2014) in the Ibiza Channel, from October 2014, are used to illustrate the toolbox capacities including its processing logs and customizable graphics options. 


\section{Toolbox description}

The toolbox is available from https://github.com/socib/glider_toolbox, without any registration or login required.

\subsection{Overview}

The SOCIB glider toolbox is composed of a set of MATLAB (MATrix LABoratory, The MathWorks Inc., 2012) or GNU Octave (Octave community, 2014) scripts and functions designed to manage the data collected by a glider fleet. There are only slight differences in terms of optimization between the code in MATLAB and in Octave (see Sect. 3.2. The toolbox supports different glider models: Slocum (G1 and G2) and Seaglider. The main stages of the data management process are covered, including metadata aggregation, data download, advanced data processing and the generation of data products and figures. Two main scripts are available to perform real-time and delayed-mode data processing, main_glider_data_processing_rt and main_glider_data_processing_dt respectively, and the other tools are controlled and called from these main scripts.

The diagram shown in Fig. 1 provides a detailed overview of the toolbox. For each step of the processing, the external resources, the internal data/metadata structures, the functions (configuring and operating) as well as the outputs (figures and files) are made explicit. The diagram is particularly useful when it comes to locating the configuration file for a given processing step, for instance, the configFigure function allows the user to set up the options for the creation of figures from the metadata and data, or to decide which variables have to appear in the netCDF file.

Since paths are configured automatically at runtime, no installation is required to run the main scripts. Hence, the user simply needs to update the various configuration files with the desired option values. The real-time processing is usually done by scheduling a task in the system hosting the toolbox that runs the respective script periodically. The delayed time processing is run manually once the files recovered from the glider are placed in the configured location. 
The SOCIB Glider Toolbox handles all navigational and science variables from any sensor integrated into the glider platform (i.e., with data recorded onto the science or navigational computer time-stamp).

The SOCIB glider toolbox is built to output three levels of netCDF files, related to different levels of processing, as defined below, and matching the processing steps described in the next section and in Fig. 1. Note the naming of the different levels can be configured by the users and so could be different from the SOCIB nomenclature used here.

Level 0 (L0): contains exactly the same data as the raw files. The file mimics the content of raw data text files but gathering all useful data in a single place. Hence, the structure of the resulting netCDF file varies for each type of glider. With the L0 files, the user goes from the engineering to the scientific domain.

Level 1 (L1): contains processed glider data, as sequences of measurements along the glider trajectory, with interpolated position coordinates to match the times of measurement by the sensor, and with unit conversions and filters applied. Additional variables are derived from the existing ones, such as salinity and potential temperature, corrected variables can also be produced, such as salinity corrected for thermal lag (see later for more details). The attributes of each variable are stored in the netCDF file, with details of any modifications. At this level the data format and variable labels follow international standards and the same for both Slocum and SeaGlider types. Derived variables currently still use the commonly established 1980s equation of state, EOS80. For now there is still no look-up table for the Mediterranean sea for the latest Gibbs functions based TEOS-10 absolute salinity calculation equation of state. Therefore there does not seem to be much point in moving to the new equation of state when the practical salinity can only be used with a small scaling constant to achieve reference salinity. Furthermore data centres are still instructed to archive practical salinity. We recommend the user entering 
the processed data into the internationally available TEOS-10 toolbox for publication purposes.

Thus L1 files store the glider data in a format ready for scientific use, building the bridge between glider mission raw data outputs and research or operational applications. The structure of these L1 files does not depend on the type of glider.

Level 2 (L2): contains gridded glider data, which means that the glider data are interpolated onto a user configured grid in the vertical and stored as vertical profiles. The profiles are obtained by interpolation of level 1 data to produce regular homogeneous and instantaneous profiles from each up or down cast, using the mean time and position of the corresponding cast for the profile location and time.

L2 files are convenient for plotting or analysis purposes, as they allow the user to work with any tool or software designed to deal with vertical profiles, such as Ocean Data View (ODV, Schlitzer, 2002).

Other models of gliders or propeller-driven AUVs could be included in the toolbox by adding programs to load the data files generated by this glider model (Level 0).

\subsection{Processing steps}

The SOCIB Glider Toolbox has 4 main processing steps, as outlined below, which take the user from the reading of raw glider data to the output of vertical gridded data profiles (see Fig. 1). Note that the toolbox is modular and flexible, such that a user can implement as many steps as required for their particular application.

\subsubsection{Step 1: Data retrieval - output Level 0 files}

In this step, the deployments to be processed are selected, the corresponding raw binary files are downloaded from the remote dock servers or base stations, converted into a human readable format, if needed, and loaded in a single and 
consistent structure that avoids working with a large number of smaller files. The user only has to configure the access to the database where the glider raw files are located (url, name, user, ...) and the query to retrieve the glider deployment information as stored in the database.

The toolbox provides support for:

- Improved Slocum raw data loading from ascii files (.dba).

- Improved Seaglider raw data loading from ascii files (.log and .eng).

- File retrieval from multiple dock servers or base stations for real-time processing.

- Deployment metadata gathering from virtually any database.

At the end of these operations, the L0 netCDF file containing a standardized product version of raw data is generated. Such a file is especially useful when the user wants to access all the engineering data from a unique file.

For example, for the CANALES-Oct-2014 Slocum mission, the L0 file contains the information that would otherwise be stored in 91 raw files generated by the manufacturer software, explicitly written in the netCDF global attributes (example available in the SOCIB THREDDS data catalogue at http:// thredds.socib.es/thredds/catalog/auv/glider/ideep00-ime_sldeep000/ L0/2014/catalog.html).

\subsubsection{Step 2: Preprocessing of raw data}

During this step, simple unit conversions and factory calibrations are applied. First, the reference sensors that measure time and horizontal positions are selected. Then, the extra navigation sensors (waypoints, pitch, depth, ...) are selected. Finally, the oceanographic sensors of interest (e.g., CTD, fluorometer, turbidity, oxygen) are selected and factory calibrations are performed. Unit conversions can also be applied if required. 


\subsubsection{Step 3: Processing - output Level 1 files}

The data processing step includes various important tasks necessary to generate robust and consistent output files. The objective of this step is to output well referenced trajectory data with derived measurements and corrections,and it is during this step that the thermal-lag correction (Garau et al., 2011) is applied.

To generate the derived measurements and corrections, operations are applied in the following order:

- Interpolation of reference coordinates (e.g. time, position) if configured by the user.

- Identification of the transect boundaries through changes of waypoint coordinates, if coordinates are available.

- Identification of profiles from dive and ascent cast boundaries, using vertical direction changes.

- Sensor processing: sensor-lag correction and thermal-lag correction, providing new variables such as salinity_corrected_thermal.

- Derivation of derived variables such as depth, potential temperature, salinity and density.

As the outcome of these operations, a Level 1 netCDF file (one file per deployment) is generated, which stores a standardized version of the trajectory data. In addition, descriptive figures from these trajectory data are created. The figure production can be modified by adapting the configuration program "configFigures".

Figure 2 shows an example of salinity profiles from CANALES-Oct-2014 after the application of the thermal-lag correction. Other scientific variables stored in the L1 file including chlorophyll concentration, oxygen concentration, salinity (un-corrected) and temperature can be plotted in a similar manner. 


\subsubsection{Step 4: Gridding - output Level 2 files}

For some applications or analysis, the user may find it more convenient to use the data as instantaneous vertical profiles, a unique longitude-latitude pair and time are derived from mean position and time and are assigned to each profile, instead of as continuous measurements along the glider trajectory, as with L1 and L0 files. Additionally during this step the user can configure the interpolation/binning of the Level 1 data, obtained in the previous step, to produce the Level 2 vertical profile netCDF data. For example, the CANALES-Oct2014 L2 file (available at http://thredds.socib.es/thredds/catalog/auv/ glider/ideep00-ime_sldeep000/L2/2014/catalog.html) contains the variable at 1440 locations, interpolated on 944 depth levels.

With these gridded fields, any profile visualisation tool can be applied to directly analyse the selected variable profiles. An example is provided with the SOCIB profile viewer (Fig. 3). In order to produce the figures, the user simply decides which variables to plot, and then selects the locations on the Geographical Profiles Selector (top-right panel). Several profiles can be visualised at the same time, allowing an immediate comparison between different locations.

\subsubsection{Differences between real-time and delayed mode}

The processing chain is similar for real-time and delayed mode data. The main difference is that step 2 is only relevant for the real-time procedure, as it is assumed that, for delayed mode data processing, the binary files are located

in the folder specified in the corresponding configuration file, as specified by the user.

\subsubsection{Summary}

The tasks undertaken in the processing chain are summarised as follows:

1. Check for configured deployments to process.

2. Download raw binary or text files from dock servers/base stations.

3. Convert deployment binary files to human readable format, if required.

4. Load data from all files in a single and consistent structure. 
5. Generate standardized product version of raw data (netCDF L0).

6. Pre-process raw data applying simple unit conversions and factory calibrations without modifying their nominal value.

7. Process data to obtain well referenced trajectory data with derived measurements and corrections.

8. Generate standardized product version of processed trajectory data (netCDF L1) and figures (Fig. 2).

9. Interpolate/bin processed data to obtain gridded data (vertical, instantaneous profiles of processed data with a configured vertical resolution).

10. Generate standardized product version of gridded data (netCDF L2) and figures from gridded data.

11. Copy data products to a public location (if required).

12. Copy figures to a public location and generate figure information service file (if required).

\subsection{Glider data specific tools}

As previously noted, some tools or common utilities included in the toolbox might be useful even if the full operational set of functions, to automatically process data from a glider fleet, are not required. These tools perform glider data specific functions that are useful in their own right. Thanks to the modular nature of the toolbox, they can be incorporated into a proprietary script or accessed from the main toolbox program.

The specific programs below are highlighted as examples of useful standalone tools for handling glider datasets:

\subsubsection{Slocum data file API}

dba2mat: loads data and metadata from a dba file.

dbacat: combines data from several dba data sets into a single data set.

dbamerge: merges data from combined navigation and science data sets into a single data set. 


\subsubsection{Seaglider data file API}

sglog2mat: loads data and metadata from a Seaglider log file.

sglogcat: combines data from several Seaglider log files.

sgeng2mat: loads data and metadata from a Seaglider eng file.

sgengcat: combines data from several Seaglider eng files.

sglogenmerge: merges data from combined Seaglider log and eng data sets into a single data set.

\section{Getting started with the glider toolbox}

\subsection{Configuration of the toolbox}

Each processing step, as defined in details in Section 2.2 can be easily configured, according to the user preferences and choices. Referring to the general diagram (Fig. 1), one can see that, for instance, two configuration functions are associated with the "processGliderData" step: one for the Slocum gliders, the other for the SeaGlider. Assuming that we are working with a SeaGlider model, the corresponding configuration function (CONFIGDATAPROCESSINGSEAGLIDER) contains all the options necessary for the processing.

\subsection{Requirements}

- MATLAB or Octave (high-level interpreted languages).

- Database driver interface (e.g., Open Database Connectivity, Java Database Connectivity).

Optional, depending on implementation:

- For the creation of netCDF files: with MATLAB, the SNCTOOLS toolbox (J. G. Evans, 2014) ; with Octave, the octcdf package (NetCDF interface for octave, Barth, 2014). 
- Slocum binary program 'dbd2asc', if binary to text conversion of Slocum datasets is to be done by the toolbox.

- libssh, if using the SFTP protocol to retrieve files remotely.

- MATLAB optimization Toolbox, if the CTD correction parameters have to be estimated.

- MATLAB General Polygon Clipping Library (GPCL), used to speed up some computation during estimation of CTD correction parameters.

Note that if some of these specific modules (sftp, optimized polygonal area computation) are required by the user for their application, they will need to build some auxiliary functions that require the compilation of interface modules written in C. Set-up helper scripts are provided to facilitate this process.

\subsection{Documentation}

The toolbox is exhaustively self-documented using the standard documentation comment system. Thus the help pages are available using the documentation browser or the "help" command. In addition an automatically generated copy of the documentation is available at http://www.socib.es/users/ glider/glider_toolbox/doc/. These pages are generated by the m2html utility (http://Www.artefact.tk/software/MATLAB/m2html/), and may be built from source by running make doc from the top directory of the toolbox.

\section{Conclusion}

The SOCIB glider Toolbox, a set of MATLAB/Octave scripts and functions, constitutes a valuable resource for processing, organising and displaying data obtained by gliders from the two main manufacturers, Teledyne Webb Research's Slocum gliders and Kongesberg's Seagliders. Glider data from other glider manufacturers could also be included in the toolbox without difficulty.

The toolbox provides all the components necessary to process the native glider data format into a set of Climate and Forecast (http://cfconventions . 
org/) compliant netCDF files that can be used for further applications. The $\mathrm{CF}$ compliance implies that the files can be used as they are in a variety of software tools, since the variables are identified through their standard names. In addition to the data files, images are automatically generated.

The toolbox is well documented and straightforward to implement for MATLAB and Octave users. It is useful for for both individual scientists and for data centres, handling large quantities of glider data that might need to be integrated to other glider data processing applications.

The SOCIB Glider Toolbox is freely available, however SOCIB should be acknowledged if the toolbox is used (see www.socib.es for details). Feedback on the operation and features of the toolbox are also always welcome and should be addressed to info @ socib.es or through bug reports on GitHub.

\section{Acknowledgements}

The development of the toolbox benefited from the Perseus FP7 project. The toolbox is provided to the scientific community for download and use under the GNU licence (http://www.gnu.org/copyleft/gpl.html) or EUPL1.1 (https://joinup.ec.europa.eu/software/page/eupl). We are indebted to the reviewers and editors for their helpful suggestions and comments during the preparation of this manuscript.

\section{References}

Álvarez, A., \& Mourre, B. (2012). Optimum sampling designs for a glider-mooring observing network. J. Atmos. Oceanic Tech., 29, 601-612. URL: http://journals.ametsoc.org/doi/full/10.1175/ JTECH-D-11-00105.1. doi:10.1175/JTECH-D-11-00105.1.

Baltes, B., Rudnick, D., Crowley, M., Schofield, O., Lee, C., Barth, J., Lembke, C., Stanitski, D., Banks, R., Snowden, D., \& Potemra, J. (2014). Toward a 
U.S. IOOS Underwater Glider Network Plan: Part of a comprehensive subsurface observing system. Technical Report U.S. IOOS. URL: http://www . ioos.noaa.gov/glider/strategy/natl_glider_ntwrk_plan_final.pdf.

Barth, A. (2014). octcdf: A NetCDF interface for octave. Package Version: 1.1.7. URL: http://octave. sourceforge.net/octcdf/.

Bouffard, J., Pascual, A., Ruiz, S., Faugère, Y., \& Tintoré, J. (2010). Coastal and mesoscale dynamics characterization using altimetry and gliders: A case study in the Balearic Sea. J. Geophys. Res., 115, C10029. URL: http://www . agu.org/pubs/crossref/2010/2009JC006087. shtml. doi:10. 1029/2009JC006087.

Bouffard, J., Renault, L., Ruiz, S., Pascual, A., Dufau, C., \& Tintoré, J. (2012). Sub-surface small-scale eddy dynamics from multi-sensor observations and modeling. Prog. Oceanogr., 106, 62-79. URL: http: //www.sciencedirect.com/science/article/pii/S0079661112000705. doi:10.1016/j . pocean .2012 .06 .007 .

Cusí, S., Torner, M., Martínez-Ledesma, M., Roque, D., Beltran, J., Ruiz, S., Casas, B., Castilla, C., Lizarán, I., Lora, S., Heslop, E., \& Tintoré, J. (2013). On the setup of an operational autonomous underwater glider facility. In 5th MARTECH International Workshop On Marine Technology (pp. 28-31).

Dobricic, S., Pinardi, N., Testor, P., \& Send, U. (2010). Impact of data assimilation of glider observations in the Ionian Sea (Eastern Mediterranean). Dynam. Atmos. Ocean, 50, 78-92. URL: http: //www.sciencedirect.com/science/article/pii/S0377026510000023. doi:10.1016/j.dynatmoce.2010.01.001.

Gangopadhyay, A., Schmidt, A., Agel, L., Schofield, O., \& Clark, J. (2013). Multiscale forecasting in the western North Atlantic: Sensitivity of model forecast skill to glider data assimilation. Cont. Shelf Res., 63, Supplement, S159 - S176. URL: http://www.sciencedirect.com/science/article/ 
pii/S0278434312002683. doi:10.1016/j.csr.2012.09.013. Coastal Ocean Observing System: Retrospective Reanalysis and Real-Time Forecasting.

Garau, B., Ruiz, S., Zhang, W. G., Pascual, A., Heslop, E., Kerfoot, J., \& Tintoré, J. (2011). Thermal lag correction on slocum CTD glider data. J. Atmos. Oceanic Tech., 28, 1065-1071. URL: http://journals.ametsoc.org/doi/ abs/10.1175/JTECH-D-10-05030.1. doi:10.1175/jtech-d-10-05030.1.

Heslop, E. (2015). Unravelling high frequency and sub-seasonal variability at key ocean circulation 'choke' points: a case study from glider monitoring in the western Mediterranean sea. Ph.D. thesis University of Southampton, Ocean and Earth Science. URL: http://eprints.soton.ac.uk/375360/.

Heslop, E., Ruiz, S., Allen, J., López-Jurado, J. L., Renault, L., \& Tintoré, J. (2012). Autonomous underwater gliders monitoring variability at "choke points" in our ocean system: A case study in the Western Mediterranean Sea. Geophys. Res. Lett., 39, L20604. URL: http://onlinelibrary.wiley.com/ doi/10.1029/2012GL053717/full. doi:10.1029/2012GL053717.

J. G. Evans (2014). SNCTOOLS toolbox. URL: http://mexcdf . sourceforge . net/index.php.

Kerfoot, J. (2014). Slocum Power Tool. URL: https://github.com/kerfoot/ spt.

Maher, D. J. (2014). Glider Data Conversion. URL: https://github.com/ DanielJMaher/Glider_Data.

Mourre, B., \& Álvarez, A. (2012). Benefit assessment of glider adaptive sampling in the Ligurian Sea. Deep-Sea Res. I, 68, 68-78. URL: http: //www.sciencedirect.com/science/article/pii/S0967063712001173. doi:10.1016/j.dsr.2012.05.010.

Octave community (2014). GNU Octave 3.8.1. URL: www.gnu.org/software/ octave/. 
Rew, R. K., \& Davis, G. P. (1990). NetCDF: An interface for scientific data access. IEEE Comput. Graph. Appl., 10, 76-82. doi:10.1109/38.56302.

Ruiz, S., Pascual, A., Garau, B., Faugère, Y., Alvarez, A., \& Tintoré, J. (2009). Mesoscale dynamics of the Balearic Front, integrating glider, ship and satellite data. J. Mar. Syst., 78 (supplement), S3-S16. URL: http://www.sciencedirect.com/science/article/ pii/S0924796309001365. doi:10.1016/j.jmarsys.2009.01.007.

Schlitzer, R. (2002). Interactive analysis and visualization of geoscience data with ocean data view. Computers $\&$ Geosciences, 28, 1211-1218. URL: http://www.sciencedirect.com/science/article/pii/ S0098300402000407. doi:10.1016/s0098-3004(02)00040-7.

Shulman, I., Rowley, C., Anderson, S., DeRada, S., Kindle, J., Martin, P., Doyle, J., Cummings, J., Ramp, S., Chavez, F., \& et al. (2009). Impact of glider data assimilation on the Monterey Bay model. Deep-Sea Res. II , 56, 188-198. URL: http://www.sciencedirect.com/science/article/ pii/S0967064508002671. doi:10.1016/j.dsr2.2008.08.003.

Teledyne Webb Research (2014). Slocum glider. Technical Report Teledyne Webb Research. URL: http://www. webbresearch.com.

The MathWorks Inc. (2012). MATLAB release R2012a. URL: https://www . mathworks.com/products/matlab/.

Tintoré, J., Vizoso, G., Casas, B., Heslop, E., Pascual, A., Orfila, A., Ruiz, S., Martínez-Ledesma, M., Torner, M., Cusí, S., Diedrich, A., Balaguer, P., Gómez-Pujol, L., Álvarez Ellacuria, A., Gómara, S., Sebastian, K., Lora, S., Beltrán, J. P., Renault, L., Juza, M., Álvarez, D., March, D., Garau, B., Castilla, C., Cañellas, T., Roque, D., Lizarán, I., Pitarch, S., Carrasco, M. A., Lana, A., Mason, E., Escudier, R., Conti, D., Sayol, J. M., Barceló, B., Alemany, F., Reglero, P., Massuti, E., Vélez-Belchí, P., Ruiz, J., Oguz, T., Gómez, M., Álvarez, E., Ansorena, L., \& Manriquez, M. (2013). SOCIB: 
The Balearic Islands Coastal Ocean Observing and Forecasting System Responding to Science, Technology and Society Needs. Mar. Technol. Soc. J., 47, 101-117. URL: http://www.ingentaconnect.com/content/mts/mtsj/ 2013/00000047/00000001/art00010. doi:10.4031/MTSJ . 47.1.10.

Troupin, C., Pascual, A., Valladeau, G., Pujol, I., Lana, A., Heslop, E., Ruiz, S., Torner, M., Picot, N., \& Tintoré, J. (2015). Illustration of the emerging capabilities of SARAL/AltiKa in the coastal zone using a multi-platform approach. Adv. Space Res., 55, 51-59. URL: http://www . sciencedirect.com/ science/article/pii/S0273117714005754. doi:10.1016/j.asr.2014.09. 011. 


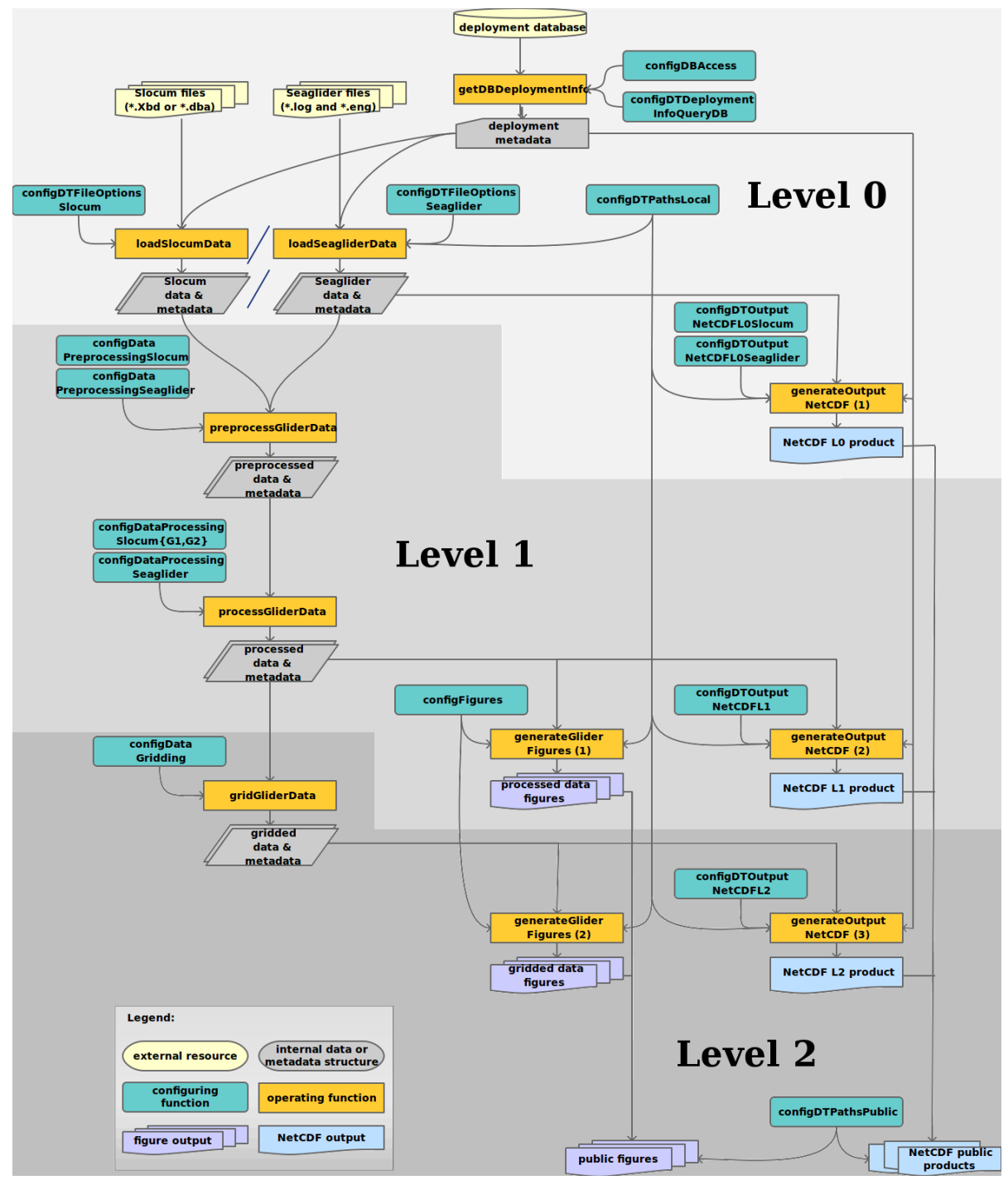

Figure 1: Glider toolbox diagram: from deployment database to figures (processed data, gridded data and public) and netCDF products (level 0,1 or 2). The names in the function boxes (blue and yellow) correspond to the MATLAB tool functions. 


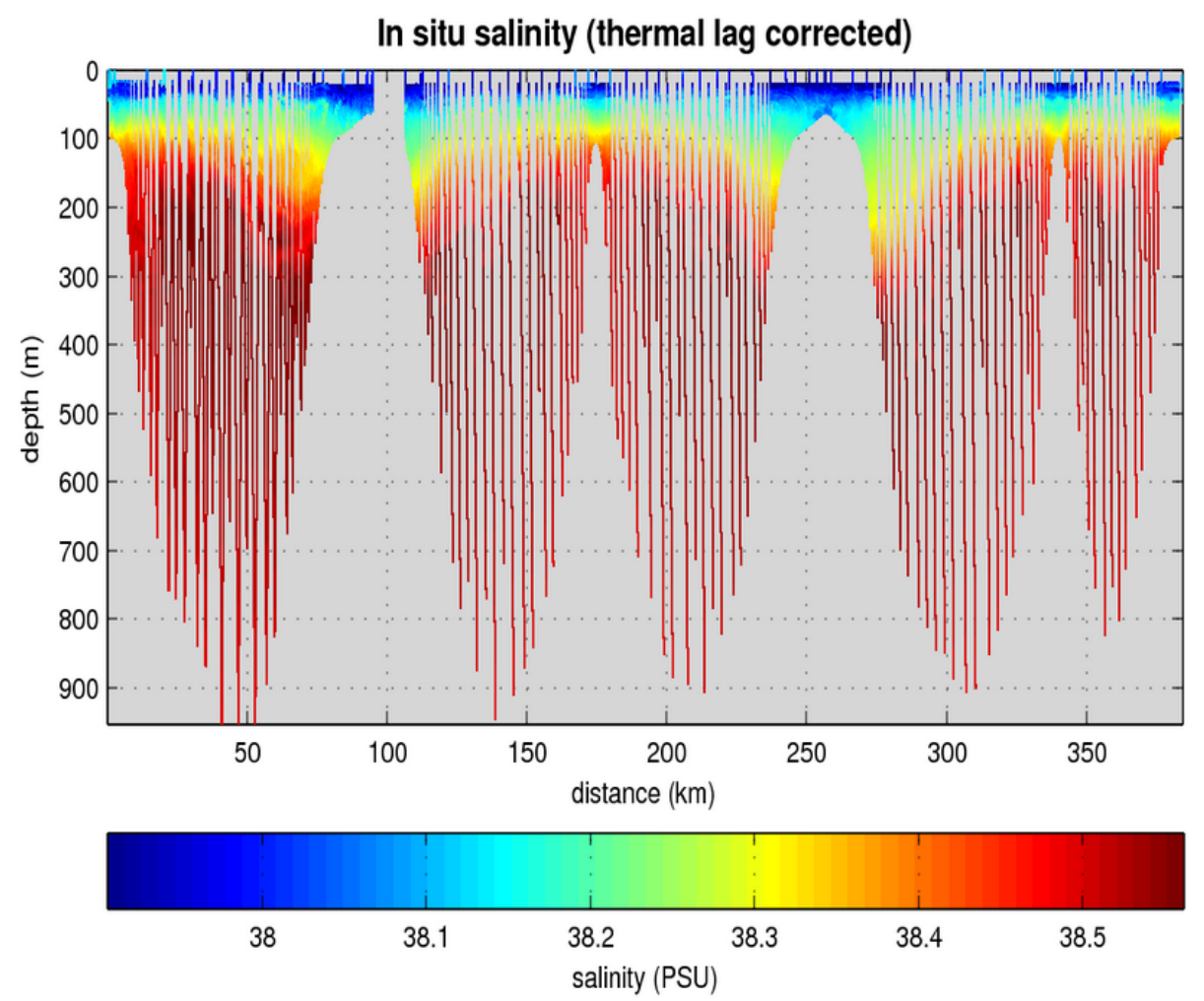

Figure 2: Thermal-lag corrected salinity as a function of distance (horizontal axis) and depth (vertical axis) during the CANALES-Oct-2014 mission. 


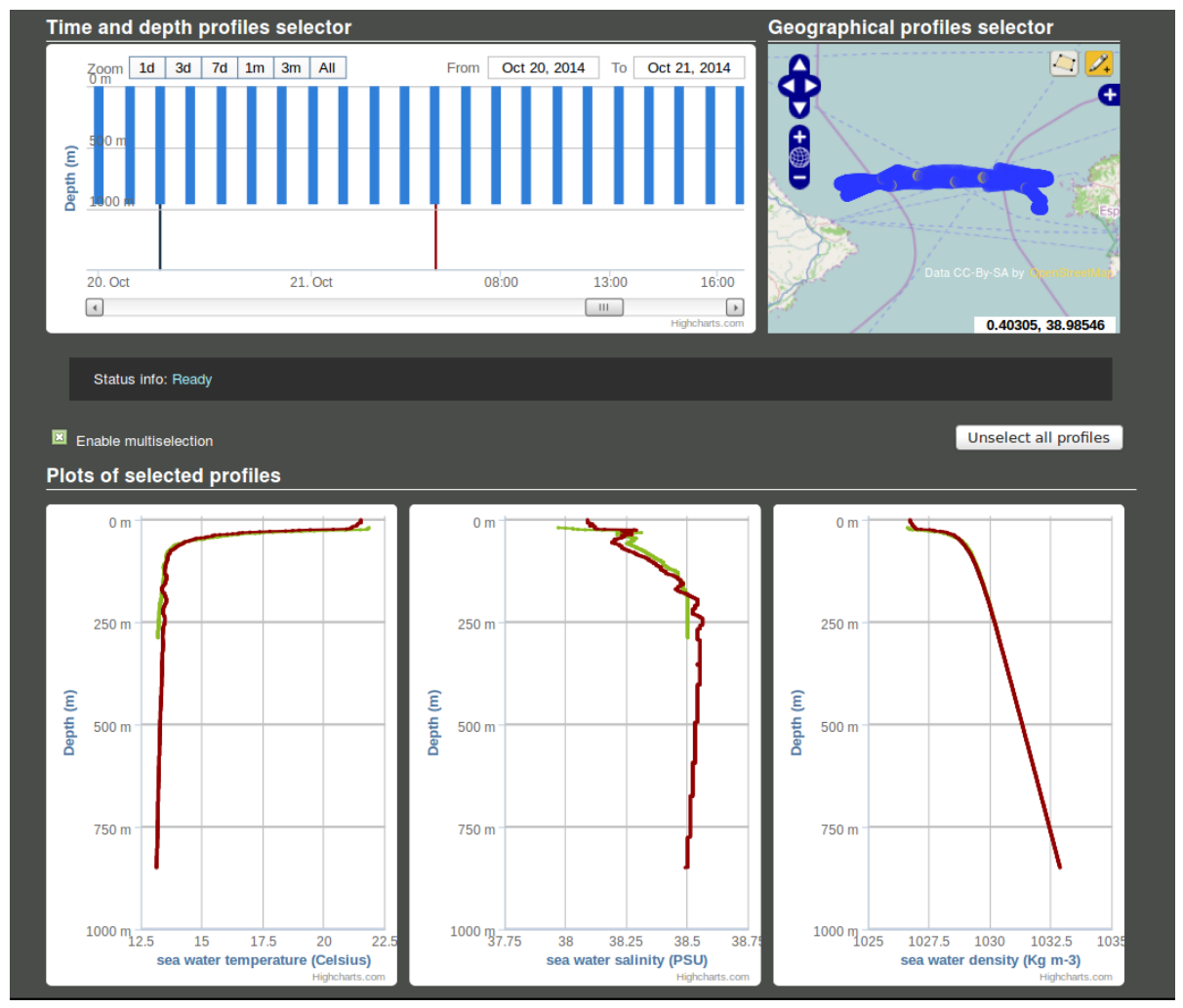

Figure 3: Temperature, salinity and density profiles at different locations in the Ibiza Channel during the CANALES-Oct-2014 mission. 